\title{
Study of clinical signs and post mortem changes in vaccinated and unvaccinated buffaloes experimentally infected with the virulent Pasturella multocida bacterium that causes hemorrhagic septicemia in buffaloes-South of Iraq • ${ }^{1}$ Jalil Abed Gatie , ${ }^{2}$ Ibrahim Abbas Mohammed \\ ${ }^{1}$ Senior scientific researcher - Veterinary Directorate - Ministry of Agriculture ${ }^{2} P h D$ in internal veterinary medicine - Veterinary Directorate - Ministry of Agriculture
}

\begin{abstract}
:
Hemorrhagic septicemia is an important disease of cattle and buffaloes. Which causes disease revolutions with great economic losses in Asia and Africa, and in Iraq it is considered one of the more dangerous diseases in buffaloes than in cows. This study was prepared to reassess the vaccination program against hemorrhagic septicemia, which is used in Iraq, especially in buffaloes, due to the nature of their lives in the marshes and as a result of the epidemic that occurred in 2008 by conducting a challenge test on buffaloes directly with a study of some physiological and immunological aspects before and after examining the challenge, as well as the effect of virulent germ The animal body has clinical symptoms and pathological changes when the post mortem is performed. This study has the advantage of using the buffalo itself by performing the challenge assay directly on it. We can depend on animal mortality, clinical symptoms and local interaction to distinguish animal resistance to the challenge test and the efficacy of the vaccine type in immunization of buffaloes against hemorrhagic septicemia. Clinical and pathological symptoms may be used on the field diagnosis of the disease and are considered as enhancement for bacterial diagnosis.
\end{abstract}

Keywords - clinical signs - buffalo - haemorrhagic septicemia - post mortem - challenge test

\section{INTRODUCTION}

Hemorrhagic septicemia is one of the main diseases that affect cows and buffaloes, which cause catastrophic epidemics in Asian and African countries that lead to high rates of infections and deaths. The disease has been recorded in mammals in many Asian and European countries and in many Asian countries epidemics often occur during the high humidity season, and in an analysis of diseases in India for the period 1979-1986, it was found that hemorrhagic septicemia caused the highest mortality rate and the second highest infection rate in cattle and buffaloes compared to foot and mouth disease, rinderpest, anthrax and black leg, respectively [1,2]. Pasteurella multocida is a Gram-negative coccobacilli , which is normal inhabitant in the nasopharyngeal area in buffalo, and the disease may occur after animals are exposed to environmental factors that help spread the disease such as high temperature, severe crowding, poor ventilation, transportation and malnutrition [3]. The Asian serotype is (B: 2) and the African serotype is (E: 2) (according to the Carter and Huddleston classification), and the two similarities to (6: B and 6: E) (according to the Namioka and Carter classification) are the two main causes of the disease. The serotype (B: 2,5) was the predominant, while the serotype (B: 
$3,4)$ was also recorded in the falo gazelle [4]. Similar cases of hemorrhagic septicemia have been reported in India (A: 1, A: 3) in cattle and buffaloes. The geographical distribution of the disease includes some regions of Asia, Africa, the Middle East and southern Europe [5]. The disease caused by the two serotypes (B: 2 or E: 2) is clinically characterized by high temperature, submandibular, throat and neck area, difficulty breathing with nasal secretions, perfuse salivation , and the disease can be above acute where clinical symptoms appear quickly and then lead In the end to death. The infection with type (A: 1 and A: 3) often includes pneumonia and death. Sepsis is the characteristic of all forms of the disease and the incubation period ranges from 3-5 days. In per acute cases, sudden death occurs without noticing any symptoms [2,3]. Buffalo, in general, are more susceptible to disease than cows (three times more) and show the strongest symptoms and more severe cases of the disease. The appearance of severe edema under the skin in the lower jaw, neck and lower chest is the characteristic of the disease. In areas where the disease is endemic, the mortality rate is limited to older calves and younger adults [6,7]. Post mortem examination of most animals that died from the disease showed severe swelling in the neck resulting from the accumulation of large bloody fluids. There are profuse hemorrhagic spots in many tissues and organs, especially in the endothelial membranes. The chest, endocardial, and abdominal cavities may contain serum and bloody fluids. The lung is clearly congested with hydrothorax, in general there is foam in the nasal cavity, trachea and bronchioles, in microscopic examination shows the presence of interstitial pneumonitis and pulmonary edema in addition to collections of neutrophils cells and macrophages in many tissues. All these changes are similar to what is observed in severe sepsis and septicemic shock. Severe epidemiological cases occur in endemic and non-endemic areas of the disease, and the disease may occur as secondary complications in cattle and buffaloes after the outbreak of FMD. It may have a loss of up to $100 \%$ if no treatment is done in the early stages of infection [3,2]. An epidemic of hemorrhagic septicemia spread in Iraq in 2008 in the buffaloes in the marshes region, where the infection rate reached 50\% in some herds and the mortality rate in infected animals was $100 \%$. In a study of this epidemic, the germ was isolated from infected and dead animals, and its agricultural and microscopic characteristics and biochemical characteristics were identified. Among the recommendations of this study was to re-evaluate the vaccination program followed in Iraq for these animals [8] and to study the clinical symptoms and post mortem characteristics. The field clinical diagnosis is very important, especially when the laboratory equipped to diagnose the germs quickly is not available in any region of the world, and the pathological symptoms during the conduct of the post mortem of the dead animals are a confirmation of the clinical diagnosis. This study recorded all the clinical and post mortem changes that local buffaloes showed when suffering from receiving the virulent bacteria, which helps veterinarians in field diagnosis of the disease in addition to the laboratory diagnosis of the bacterium.

\section{MATERIALS AND METHODS}

24 heads of buffalo calves at the age of 3-6 months were collected and entered into a pre-prepared enclosure that was sealed and equipped with adequate livestock for the buffaloes. The animals were numbered, their information was recorded, and they were left for observation for a month. They were treated against external and internal parasites. Their behavior was observed to ensure their health and suitability for research. They also received the foot and mouth disease vaccine to protect them from this disease. Six healthy domestic rabbits, previously unvaccinated against $P$. multocida, were used to pass the strain used in them, to maintain it virulence, and to examine the virulence of the bacterium during the two challenge tests. Three vaccines were prepared at Al-Kindi [Company for the production of vaccines and 
veterinary medicines] depending on the methods mentioned in (OIE Manual) [9] and as follows. A broth culture of $P$. multocida (Carter B) strain used in the production of the vaccine was prepared at Al-Kindi Company. The live bacterial count and the dry weight of the culture precipitate (sample culture prepared above) were performed. The liquid culture was divided into three sections to prepare three types of vaccines: (HS / APV), the combination of haemorrhagic septicemia and black leg with alum (HS + BQ / APV) and the oily haemorrhagic septicemia vaccine (OAV). Challenge test dose: The virulent strain of $P$. multocida bacterium used in the production of the haemorrhagic septicemia vaccine was used in the Al-Kindi company after it was passed into the rabbit to strengthen it and ensure its purity and the bacterial count was carried out where it was injected at a concentration of $10^{9}$ germs $/ \mathrm{cm}^{3}$ subcutaneously per animal in the first challenge test and at a concentration of $10^{8} \mathrm{Germ} / \mathrm{cm}^{3}$ subcutaneously for each animal in the second challenge assay, with a dose of $0.1 \mathrm{~cm}^{3}$ by subcutaneous injection method for each rabbit during the two challenge tests each in a timely manner.

Animal vaccination and groups distribution.

The animals were divided into four groups (each group consists of 6 animals), as follows:

The first group (I): inoculated with the H. S vaccine precipitated with alum at a dose of $3 \mathrm{~cm}^{3}$ (HS / APV) subcut in two doses between them for a period of (21) days and included the numbers 1,3,30, 4, 27, 62,

The second group (II): inoculated with the mixed vaccine, from H.S at a dose of $3 \mathrm{~cm}^{3}$ and B.1 at a dose of $2 \mathrm{~cm}^{3}$, precipitated with alum (HS + B.L / APV) subcutaneously in two doses between them for a period of (21) days. The numbers included $10,12,24,11,13,21$,

The third group (III): were inoculated with the oily vaccine at a dose of $3 \mathrm{~cm}^{3}$ (OAV) intramuscle for one time only and included the numbers $6,9,23,5,7,22$

The fourth group (IV): was injected with a physiological salt solution $\left(3 \mathrm{~cm}^{3}\right)$ subcut as a control group and included the numbers $14,16,28,8,15,25$. Table (1) shows the distribution of animals into groups

Table (1) shows the distribution of animals into groups

\begin{tabular}{|l|l|l|r|}
\hline & \multicolumn{1}{|}{$\begin{array}{r}\text { Second challenge } \\
\text { test }\end{array}$} & First challenge test & Vaccine type \\
\hline 1 & $4,27,62$ & $1,3,30$ & Alum precipitant H.S vaccine \\
\hline 11 & $11,13,21$ & $10,12,24$ & $\begin{array}{r}\text { Alum precipitant mixed H.S } \\
\text { and B.L vaccines }\end{array}$ \\
\hline 111 & & & Oily vaccine \\
\hline $1 \mathrm{~V}$ & $6,9,23$ & $5,7,22$ & Control \\
\hline
\end{tabular}

\section{Challenge test}

The groups were re-divided, each group into two parts, and each subgroup consisted of three animals, in order to use each subgroup for each challenge test. The challenge test was carried out in two stages. The first was 21 days after the second vaccination dose (day 42). The second challenge test was more than six months after the first vaccination dose. The results were recorded on both testes and the effect of the challenge dose on the animals was visualized. The control group was divided into two parts, three animals were considered positive control who received a dose of virulent bacteria during 
the first challenge test and the other three were considered negative control that received physiological salt solution during the same examination. These animals were used as a control group during the second challenge test.

\section{The first challenge test.}

The general condition of the animals was observed, and the temperature of all group elements was recorded before performing a challenge test to assess the health status and blood samples were collected The germ was given to three animals at a dose of $3 \mathrm{~cm}^{3}$ (by subcutaneous administration in the neck) from groups inoculated with the three types of vaccines (the first group of numbers 1-30-3) (the second group of numbers 10-12-24) (the third group of numbers 5-7 22). ( Same dose of bacteria was given the to three animals from the control group, which are numbers 14-16-28. The remainder of the control group was given $3 \mathrm{~cm}^{3}$ of physiological salt solution, which are numbers 8-15-25 For the purpose of verifying the virulence of the germ and confirming its action, the same bacterial culture was given at a dose of $0.1 \mathrm{~cm}^{3}$ to three rabbits, in good health and previously unvaccinated against the germ, in the femoral fold and placed under supervision.

\section{The second challenge test}

The germ was administered to three animals from the groups inoculated with the three types of vaccines (first group numbers 4-27-62) (second group numbers 11-13-21) (third group numbers 6-9-23) And the germ was given in the same dose to three animals from the control group, which are numbers (8-15-25). For the purpose of verifying the virulence of the germ and confirming its action, the same bacterial culture was given at a dose of $0.1 \mathrm{~cm} 3$ to three rabbits, in good health and previously unvaccinated against the germ, in the femoral fold and placed under supervision.

\section{Environment protection}

A pit was prepared (prior to the execution of the challenge testes each in a timely manner) at a depth of $1.5 \mathrm{~m}$ in which the dead animals and necropsy residues were buried so that they could not be dug up or exposed, medical materials were prepared to sterilize the necropsy area and all the regular and medical tools and supplies used. Statistics: The results were analyzed statistically by using the statistical analysis program SPSS Version 17, L.S.D., ( $\mathrm{P} \leq 0.05$ ( The capital letters in English were used horizontally to denote the differences between the groups. Small letters were also used vertically to denote the differences between days during the experiment The values in the tables represent the mean \pm the standard error the different capital letters express the significant differences between the groups. The different small letters represent the significant differences between the days within the group.

\section{III.RESULTS}

The results showed in the first challenge test, death of all positive control animals (the first group, which is three animals) on the second day, at a rate of $100 \%$, and one of the animals from the mixed vaccine group (the second group) perished six days after the performance of the challenge test, at a rate of 33.3\% and eight animals survived out of nine vaccinated animals received the virulent bacterium, at a rate of $88.8 \%$, despite suffering from severe inflammation at the injection site and the body reacted vigorously through high temperature and increase of other physiological activities. The following signs were recorded on the animals in the positive control group 
The animals seemed to be in a state of shock, the temperature was below the normal range, the head drooping and fluids coming out of the mouth and nose, lethargy and complete interruption of appetite and stillness in one place then lying down, severe congestion in the mucous membranes of the eyes, enlarged perscapulare lymph nodes, increase of heartbeat and breathing, then decline Rapid breathing and heart before death, difficulty breathing and hearing voices that express bronchitis and lungs, severe swelling in the area of germ injection in the neck painful, hard and hot, larynx swelling was not noticed clearly in the three animals, the heart rate fell to $44 / \mathrm{m}$ and the body temperature was at a rate of / $37 \mathrm{c}^{0}$ before death, and the rattle and bellowing sounds were heard before the death of the animals. It is a characteristic sound of hemorrhagic septicemia in buffalo. The significant clinical signs were recorded in the three vaccinated groups. As shown in Table 2.

The three rabbits that received the virulent bacterium died, and the results of the bacterial culture of samples from the heart blood showed the presence of the germ, as well as the results of direct staining (Gram stain) of heart blood smears in all rabbits are positive, as shown in picture 1.

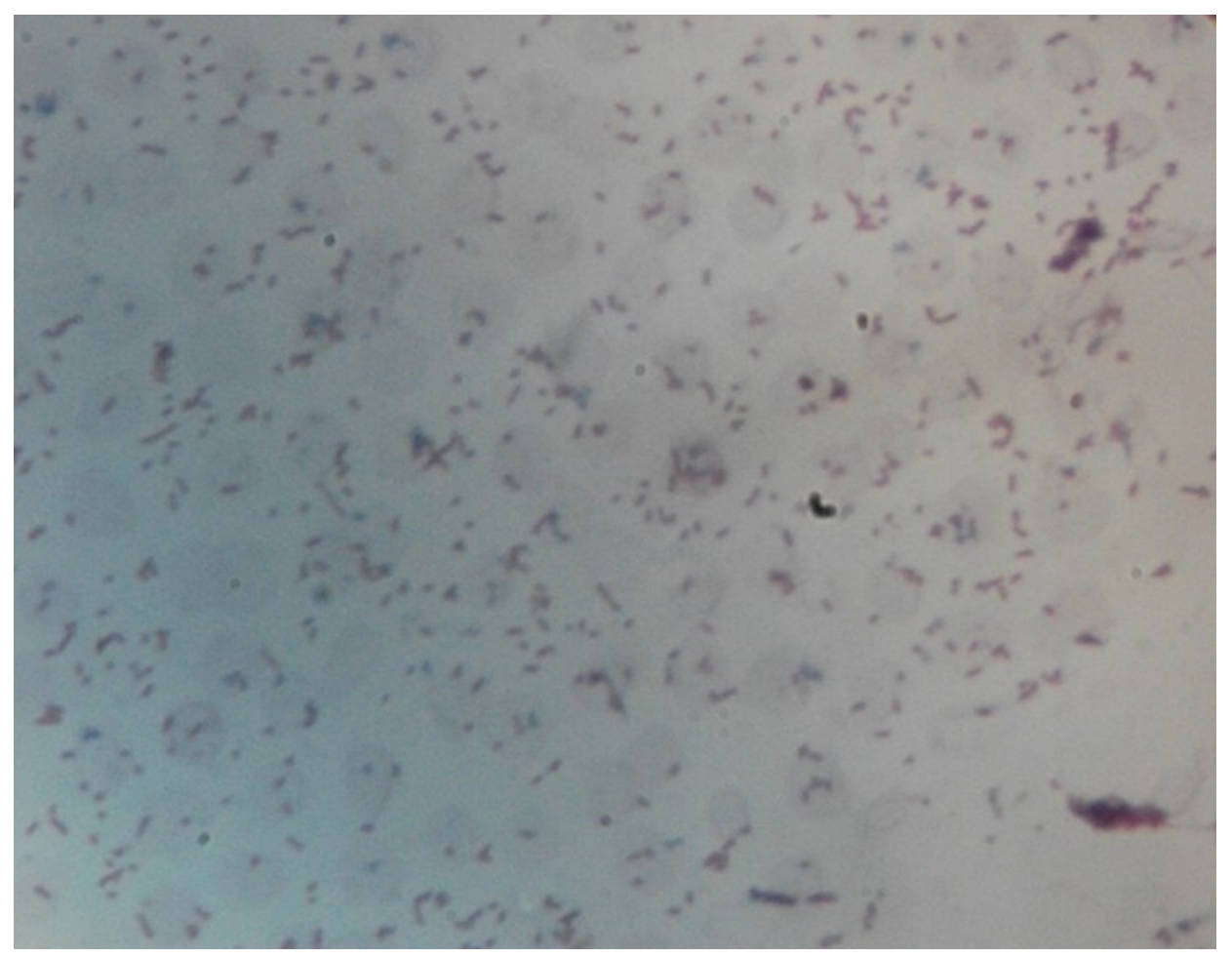

Picture (1) shows a blood smear from the dead rabbit during the first challenge

Group I (H.S / APV)

The group showed lethargy, fatigue, and partial appetite during the first and second days, and on the third day, it returned to its activity with the appearance of a swelling at the injection area with dimensions of $10 \times 10 \mathrm{~cm}$, except for animal No. 30 , as it appeared lameness and increased it and spread to the shoulder and to the neck area, and then died on the sixth 
day post mortem was performed, samples of blood and body fluids were implanted to confirm and isolate pathogen, as shown later..

\section{Group II (II): (H.S + B.L / APV)(}

This group showed lethargy, fatigue and partial appetite at the first and second days, in the third day, it returned to its activity with the appearance of a swelling at the injection area $10 \times 10 \mathrm{~cm}$, except for animal No. 12, which increased to $12 \times 15 \mathrm{~cm}$, but all of them disappeared after several days. Group (III): (OAV) This group showed the least local reaction and the fastest disappearance. Table (2) shows a summary of the results of the first challenge test as shown in pictures (216). .

Table 2 shows the interaction of animals with virulent bacteria after performing the first challenge assay

\begin{tabular}{|c|c|c|c|}
\hline Groups & Animal No & Vaccine type & Interact after a challenge dose \\
\hline \multirow[t]{3}{*}{ Group 1} & 1 & Precipitated alum H.S & Local swelling $10 * 10 \mathrm{~cm}$ \\
\hline & 3 & Precipitated alum H.S & Local swelling $10 * 10 \mathrm{~cm}$ \\
\hline & 30 & Precipitated alum H.S & $\begin{array}{r}\text { After } 72 \text { hours, a localized swelling appeared at } \\
\text { the injection area and spread to the neck area, and } \\
\text { then the animal died within five days }\end{array}$ \\
\hline \multirow[t]{3}{*}{ Group 2} & 10 & $\begin{array}{r}\text { Mixd of H.S andB.L } \\
\text { precipitant alum }\end{array}$ & Local swelling $10 * 8 \mathrm{~cm}$ \\
\hline & 12 & $\begin{array}{r}\text { Mixd of H.S andB.L } \\
\text { precipitant alum }\end{array}$ & Local swelling $12 * 15 \mathrm{~cm}$ \\
\hline & 24 & $\begin{array}{r}\text { Mixd of H.S andB.L } \\
\text { precipitant alum }\end{array}$ & Local swelling $10 * 10 \mathrm{~cm}$ \\
\hline \multirow[t]{3}{*}{ Group 3} & 5 & Oily H.S & No reaction \\
\hline & 7 & Oily H.S & Local swelling $5 * 5 \mathrm{~cm}$ \\
\hline & 22 & Oily H.S & Local swelling $5 * 5 \mathrm{~cm}$ \\
\hline \multirow{3}{*}{$\begin{array}{r}\text { Group } 4 \\
\text { Control- } \\
\text { group }\end{array}$} & 14 & Control & Died within 23 hours \\
\hline & 16 & Control & Died within 14 hours \\
\hline & 28 & Control & Died within 12 hours \\
\hline
\end{tabular}

characteristic of the animals of the first group No. 14,16 and 28 Post mortem Swelling of the injection site in the neck, severe congestion in the mucous membranes of the eyes, enlarged of per scapular lymph nodes, sunken eyes, slight enlargement of the throat, bleeding in the spleen, blood not clotting, severe congestion of the lungs, congestion and bleeding in the liver, inflammation of the subcutaneous tissue in neck and the presence of inflammatory serous fluid.

\section{Clinical symptoms and anatomical characteristics of animal No. 30}

The tumor developed on the fifth day after the first challenge test in animal No. 30 of the first group and spread to cover the neck and part of the subsholder. On the sixth day, signs increased with congestion of the eyes, dyspnea, swelling spread to the entire head and front of the chest and the front legs, the inability to stand with the head drooping and then the animal lying down with strong snoring, drooling saliva ,nasal discharge, then the animal died on the evening of the same day. This animal was used as a model for the emergence of pathological signs as it showed all the clinical symptoms of the disease due to its long survival that allowed the observation of pathological changes when the post mortem was performed. When performing post mortem, the following was observed: Inflammation and swelling of the subcutaneous tissue and the presence of yellow blood serous fluids (in swelling areas) 
Severe inflammation of the lungs, black spots on their surface, and blood serous fluids in the chest cavity Hemorrhagic patches on the heart muscle (petechial hemorrhage) and blood clots in the heart only Laryngitis and treacheitis Severe congestion in the small intestine and enlarged mesenteric lymph nodes. Pictures (15-21) show the pathological changes of animal No. 30 Samples were collected from heart blood and fluids collected in the thoracic and subcutaneous cavities for bacterial culture, and the presence of the germ was confirmed as shown in pictures (2-24).

\section{Temperature}

The results showed an insignificant increase in temperature after performing the first challenge test in the animals injected with the challenge dose. It reached 1.3 - 2.3 Celsius degrees higher than normal rates on days 4 and 5 (the temperature was measured on days 1 and 2 before the challenge test, which began on day 3 in the evening and continued measurement up to ten days after the challenge test) and then its fall to normal rates compared to the negative control animals. Positive control animals (which received the challenge dose), they died before the temperature rise was recorded in them after the challenge. There were no clear differences in temperature or statistically significant between the groups of animals. The inoculated animal except in animal No. (30), where it reached $42 \mathrm{C}^{0}$ on the fourth day after the challenge, and then died after that. Table (3) shows the temperature results.

Table (3) shows the results of the temperature before and after the first challenge examination

\begin{tabular}{|c|c|c|c|c|c|}
\hline Days Groups & Group 1 & Group 2 & Group 3 & Group 4 & L.S.D \\
\hline Day 1 & $\begin{array}{r}39.23 \pm 0.03 \mathrm{C} \\
A B\end{array}$ & $\begin{array}{r}38.96 \pm 0.26 c \\
A B\end{array}$ & $\begin{array}{r}39.60 \pm 0.45 b \\
A\end{array}$ & $\begin{array}{r}38.60 \pm 0.45 a \\
B\end{array}$ & 0.72 \\
\hline Day 2 & $\begin{array}{r}38.50 \pm 0.32 \mathrm{c} \\
\mathrm{A}\end{array}$ & $\begin{array}{r}38.43 \pm 0.23 \mathrm{c} \\
\mathrm{A}\end{array}$ & $\begin{array}{r}39.10 \pm 0.37 b \\
A\end{array}$ & $\begin{array}{r}39.16 \pm 0.60 \mathrm{ab} \\
\mathrm{A}\end{array}$ & 1.06 \\
\hline $\begin{array}{r}\text { Day 3-First } \\
\text { challenge test }\end{array}$ & $\begin{array}{r}38.83 \pm 0.20 \mathrm{c} \\
\mathrm{A}\end{array}$ & $\begin{array}{r}38.90 \pm 0.11 \mathrm{c} \\
\mathrm{A} \\
\end{array}$ & $\begin{array}{r}39.23 \pm 0.44 b \\
A\end{array}$ & $\begin{array}{r}38.33 \pm 0.13 b c \\
A\end{array}$ & 0.67 \\
\hline Day 4 & $\begin{array}{r}40.63 \pm 0.03 a b \\
A \\
\end{array}$ & $\begin{array}{r}40.66 \pm 0.12 a \\
A \\
\end{array}$ & $\begin{array}{r}40.90 \pm 0.05 a b \\
A \\
\end{array}$ & $\begin{array}{r}38.06 \pm 0.06 \mathrm{c} \\
\mathrm{B}\end{array}$ & 0.64 \\
\hline Day 5 & $\begin{array}{r}41.10 \pm 0.49 \text { a } \\
A \\
\end{array}$ & $\begin{array}{r}40.16 \pm 0.26 a b \\
B \\
\end{array}$ & $\begin{array}{r}41.20 \pm 0.32 a \\
A \\
\end{array}$ & $\begin{array}{r}38.83 \pm 0.03 b \\
C\end{array}$ & 0.85 \\
\hline Day 6 & $\begin{array}{r}41.10 \pm 0.55 a \\
\mathrm{~A} \\
\end{array}$ & $\begin{array}{r}39.93 \pm 0.06 b \\
A B \\
\end{array}$ & $\begin{array}{r}40.63 \pm 0.57 a b \\
A \\
\end{array}$ & $\begin{array}{r}38.93 \pm 0.13 a b \\
B \\
\end{array}$ & 1.06 \\
\hline Day 7 & $40.40 \pm 0.80 \mathrm{ab}$ & $\begin{array}{r}39.83 \pm 0.29 b \\
A \\
\end{array}$ & $\begin{array}{r}39.66 \pm 0.37 b \\
A \\
\end{array}$ & $\begin{array}{r}38.66 \pm 0.17 b c \\
A \\
\end{array}$ & 1.24 \\
\hline Day 8 & $\begin{array}{r}39.53 \pm 0.14 b c \\
A \\
\end{array}$ & $\begin{array}{r}39.73 \pm 0.31 b \\
A \\
\end{array}$ & $\begin{array}{r}39.86 \pm 0.44 b \\
A \\
\end{array}$ & $\begin{array}{r}39.20 \pm 0.32 a b \\
A \\
\end{array}$ & 0.74 \\
\hline Day 9 & $\begin{array}{r}40.10 \pm 0.05 \mathrm{~b} \\
\mathrm{~A} \\
\end{array}$ & $\begin{array}{r}40.16 \pm 0.21 \mathrm{ab} \\
\mathrm{A} \\
\end{array}$ & $\begin{array}{r}40.53 \pm 0.65 a b \\
A \\
\end{array}$ & $\begin{array}{r}38.76 \pm 0.39 b \\
B \\
\end{array}$ & 0.46 \\
\hline Day 10 & $\begin{array}{r}39.40 \pm 0.17 b c \\
A\end{array}$ & $\begin{array}{r}40.66 \pm 0.03 a \\
A\end{array}$ & $\begin{array}{r}40.30 \pm 0.52 \mathrm{ab} \\
\mathrm{A}\end{array}$ & $\begin{array}{r}39.86 \pm 0.29 a b \\
A\end{array}$ & 2.14 \\
\hline Day 11 & $\begin{array}{r}40.0 \pm 0.03 b c \\
A \\
\end{array}$ & $\begin{array}{r}40.30 \pm 0.60 a b \\
A \\
\end{array}$ & $\begin{array}{r}40.06 \pm 0.46 b \\
A \\
\end{array}$ & $\begin{array}{r}38.76 \pm 0.23 b \\
B \\
\end{array}$ & 0.30 \\
\hline Day 12 & $\begin{array}{r}39.33 \pm 0.08 b c \\
B\end{array}$ & $\begin{array}{r}39.70 \pm 0.05 b \\
A\end{array}$ & $\begin{array}{r}39.63 \pm 0.35 b \\
A B \\
\end{array}$ & $\begin{array}{r}39.13 \pm 0.06 a b \\
B\end{array}$ & 0.24 \\
\hline Day 13 & $\begin{array}{r}40.0 \pm 0.05 b c \\
A\end{array}$ & $\begin{array}{r}40.16 \pm 0.33 \\
A\end{array}$ & $\begin{array}{r}40.10 \pm 0.58 b \\
A\end{array}$ & $\begin{array}{r}38.93 \pm 0.06 a b \\
B \\
\end{array}$ & 0.17 \\
\hline
\end{tabular}




\begin{tabular}{l|l|l|l|l|} 
L.S.D & 0.87 & 0.65 & 1.10 & 0.68 \\
\hline
\end{tabular}

\section{The second challenge}

The second challenge test was carried out after six months of inoculation with the booster dose (and seven months after the oil vaccine dose), but by using a challenge dose with a concentration lower than the first challenge $\left(8^{10}\right)$ bacteria $/ \mathrm{cm}^{3}$ to rely on clinical symptoms only without animal mortality and the results were as follows:

Control group: lost one of the animals after 10 days of injection (the animal was dissected, the germ was isolated, examined under a microscope, and the colonies' specifications were viewed to confirm the cause). The second animal showed a local reaction of a swelling $(5 \times 7) \mathrm{cm}$ for a period of 14 days. And the third showed a slight swelling on the neck and then disappeared after several days.

The group of alum H.S vaccine, one of the animals showed a local reaction $(5 \times 7) \mathrm{cm}$ for 7 days, and the other $(2 \times 2)$ $\mathrm{cm}$ for 7 days, and the third did not show any reaction.

The mixd precipitated alum H.S\&B.L, a local reaction $(5 \times 7) \mathrm{cm}$ appeared on one of them and the other $(2 \times 2) \mathrm{cm}$ for 5 days, and the third did not show any reaction..

Oily vaccine group: A local reaction $(2 \times 2) \mathrm{cm}$ was shown for 5 days on one of them, and the other two did not show any reaction. Table 4 shows a summary of the results of the second challenge test.

The three rabbits that received the virulent bacterium are died, and the results of the bacterial culture of samples from the heart blood showed the presence of the germ, as well as the results of direct staining (Gram stain) by smears from the heart blood in all the rabbits .

Table (4) shows the clinical signs after performing the second challenge test

\begin{tabular}{|c|c|c|c|}
\hline Groups & Animal No & Vaccine type & Reaction after challenge test \\
\hline \multirow[t]{3}{*}{ Group1 } & 4 & H.S & Local swelling $7 \times 5$ for 7 days \\
\hline & 27 & H.S & Local swelling $7 \times 5$ for 7 days \\
\hline & 62 & H.S & $\begin{array}{ll}\text { No reaction } \\
\end{array}$ \\
\hline \multirow[t]{3}{*}{ Group2 } & 11 & H.S\&B.L & Local swelling $7 \times 5$ for 7 days \\
\hline & 13 & H.S\&B.L & Local swelling $2 \times 2$ for 5 days \\
\hline & 21 & H.S\&B.L & No reaction \\
\hline \multirow[t]{3}{*}{ Group3 } & 6 & Oily H.S & Local swelling $2 \times 2$ for 5 days \\
\hline & 9 & Oily H.S & $\begin{array}{l}\text { No reaction } \\
\end{array}$ \\
\hline & 23 & Oily H.S & No reaction \\
\hline \multirow{3}{*}{$\begin{array}{l}\text { Group4 } \\
\text { control }\end{array}$} & 15 & Control & Local swelling $7 \times 5$ for 14 days \\
\hline & 25 & Control & $\begin{array}{r}\text { Swelling on neck and death in } 10 \\
\text { day }\end{array}$ \\
\hline & 8 & Control & $\begin{array}{r}\text { Small swelling on neck } \\
\text { disappear during some days }\end{array}$ \\
\hline
\end{tabular}




\section{University of Thi-Qar Journal of agricultural research}

ISSN Onlin:2708-9347, ISSN Print: 2708-9339 Volume 10, Issue 1 (2021) PP 104 -122

https://jam.utq.edu.iq/index.php/main $\quad$ https://10.54174/UTJagr.Vo10.N1/12

\section{Pictures}

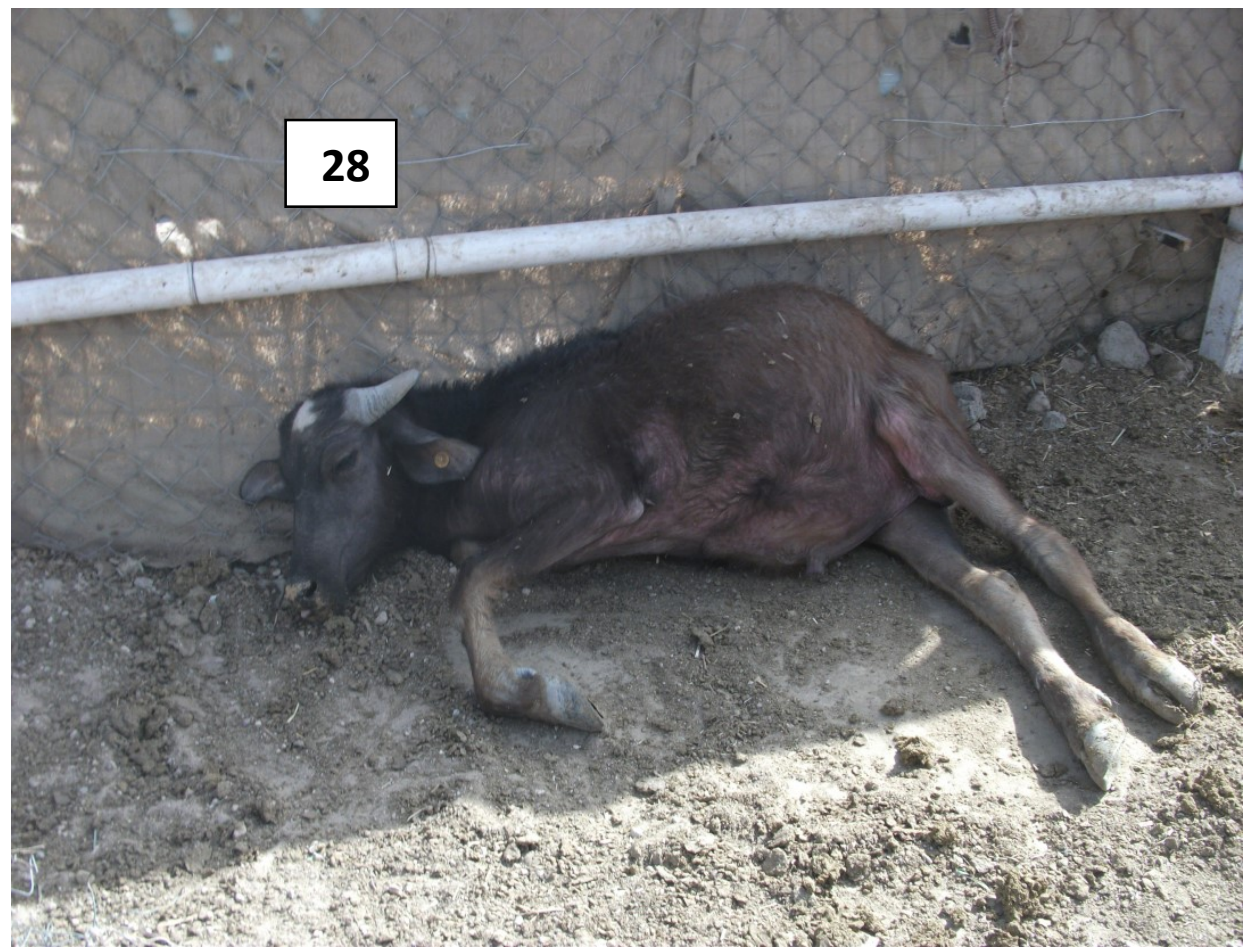

Picture (2) shows the animal No28 after its rapid death due to receiving the first challenge dose

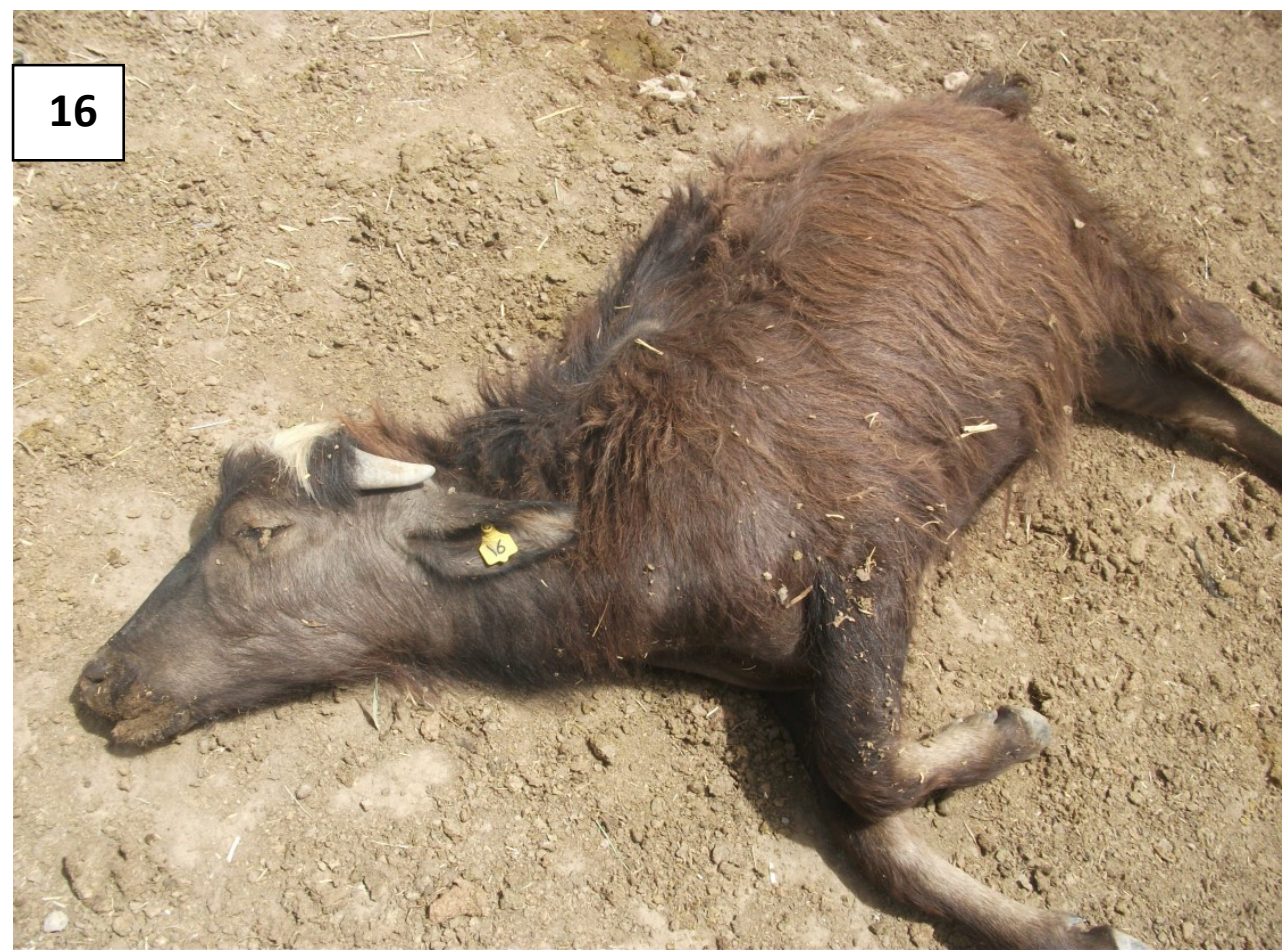

Picture (3) shows the animal No16 after its rapid death due to receiving the first challenge dose 


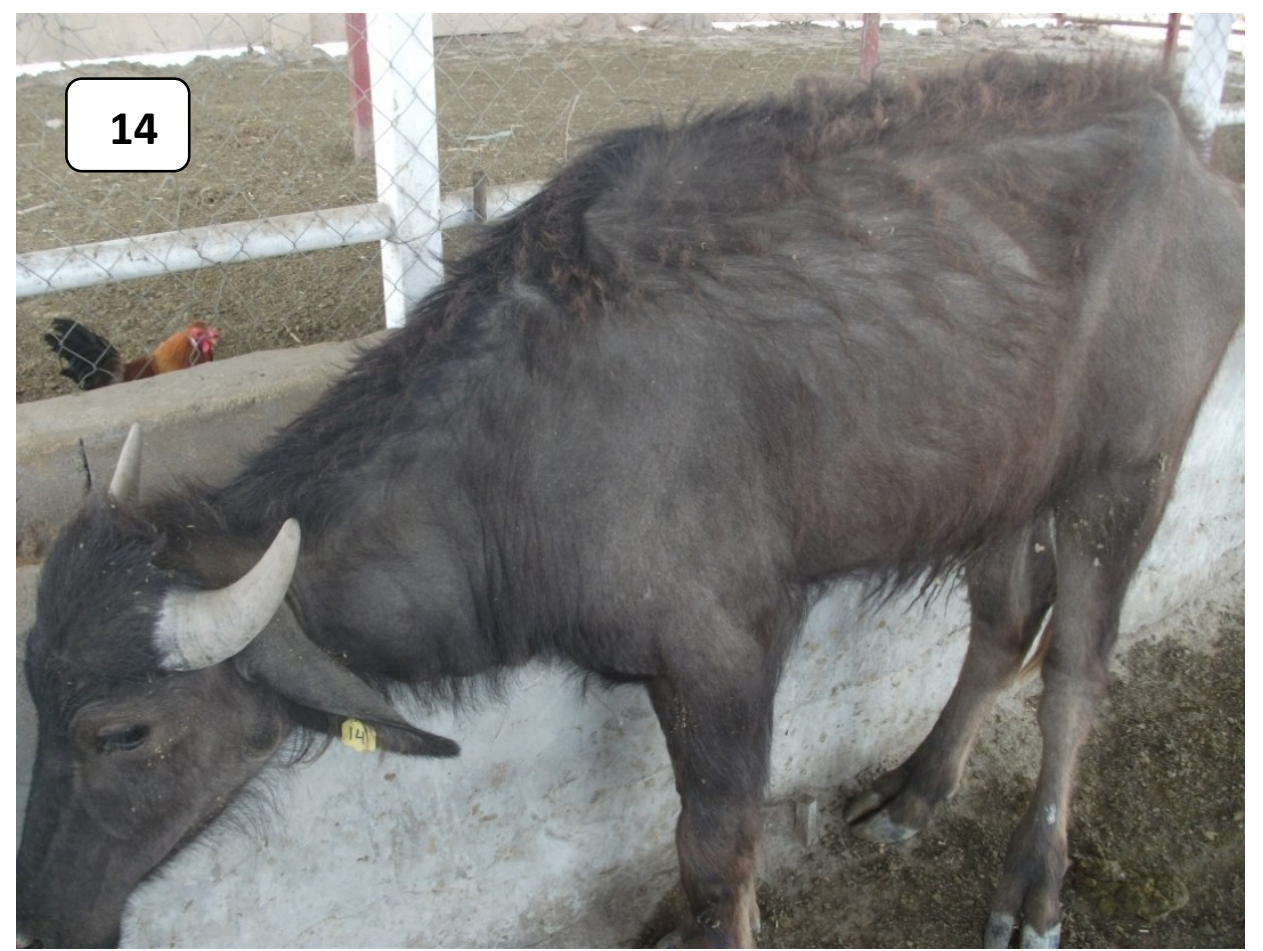

Picture (4) shows the animal No 14 before its death due to the first challenge test

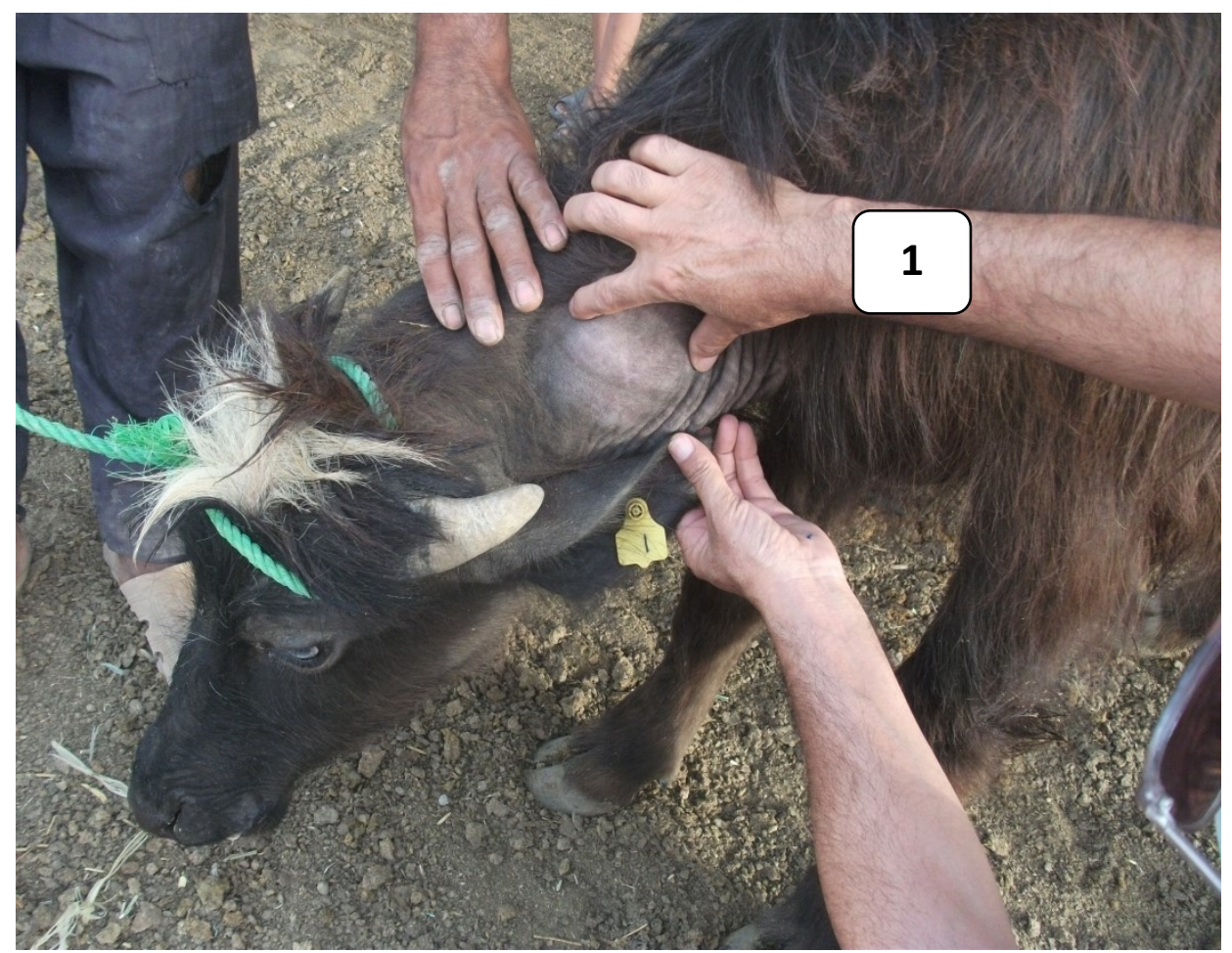

Picture (5) shows the inflammatory reaction in the neck on Animal No. 1 after performing the first challenge test 


\section{University of Thi-Qar Journal of agricultural research}

ISSN Onlin:2708-9347, ISSN Print: 2708-9339 Volume 10, Issue 1 (2021) PP 104 -122 https://jam.utq.edu.iq/index.php/main $\quad$ https://10.54174/UTJagr.Vo10.N1/12

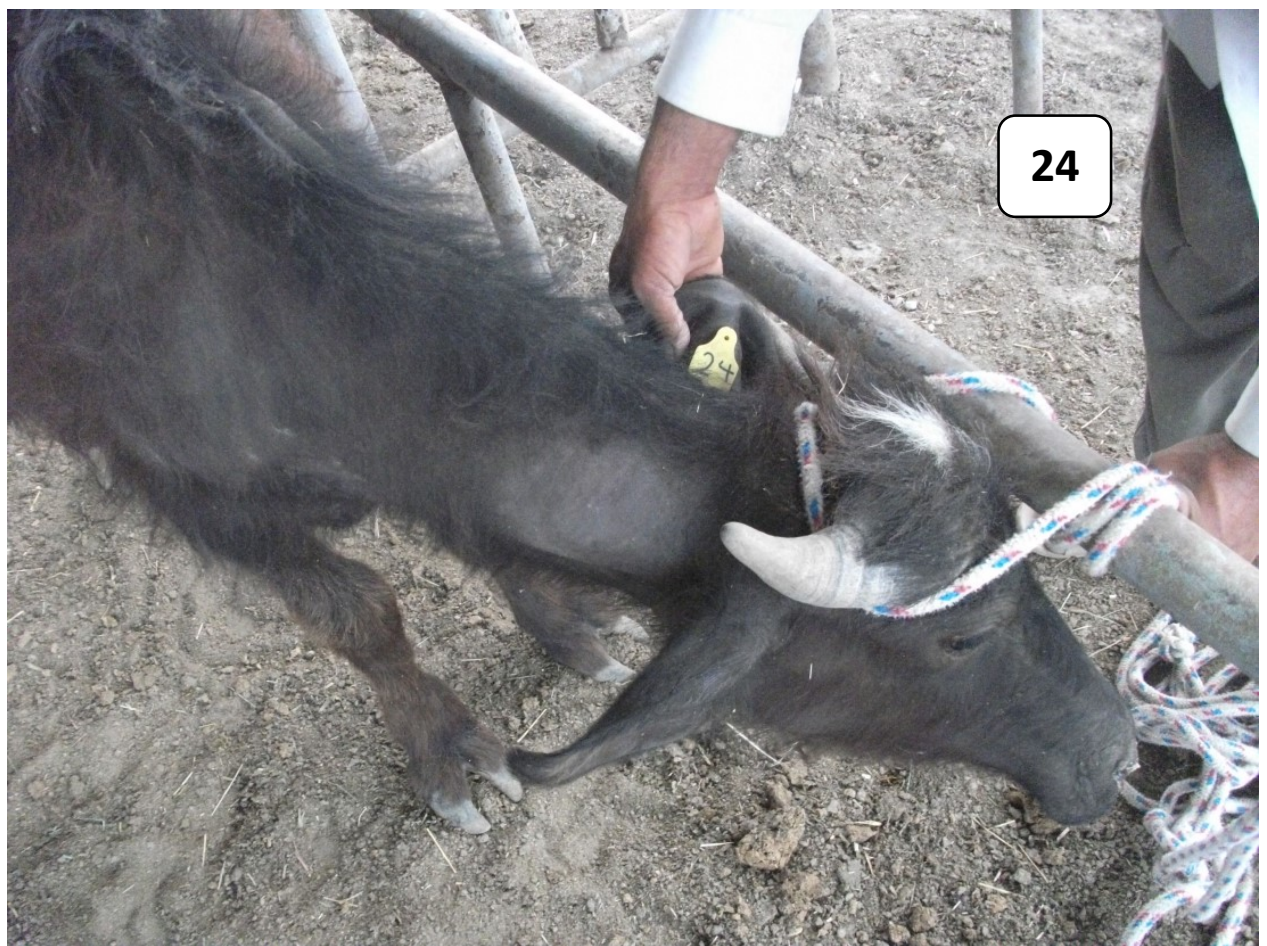

Picture (6) shows the inflammatory reaction in the neck on animal No. 24 after performing the first challenge test

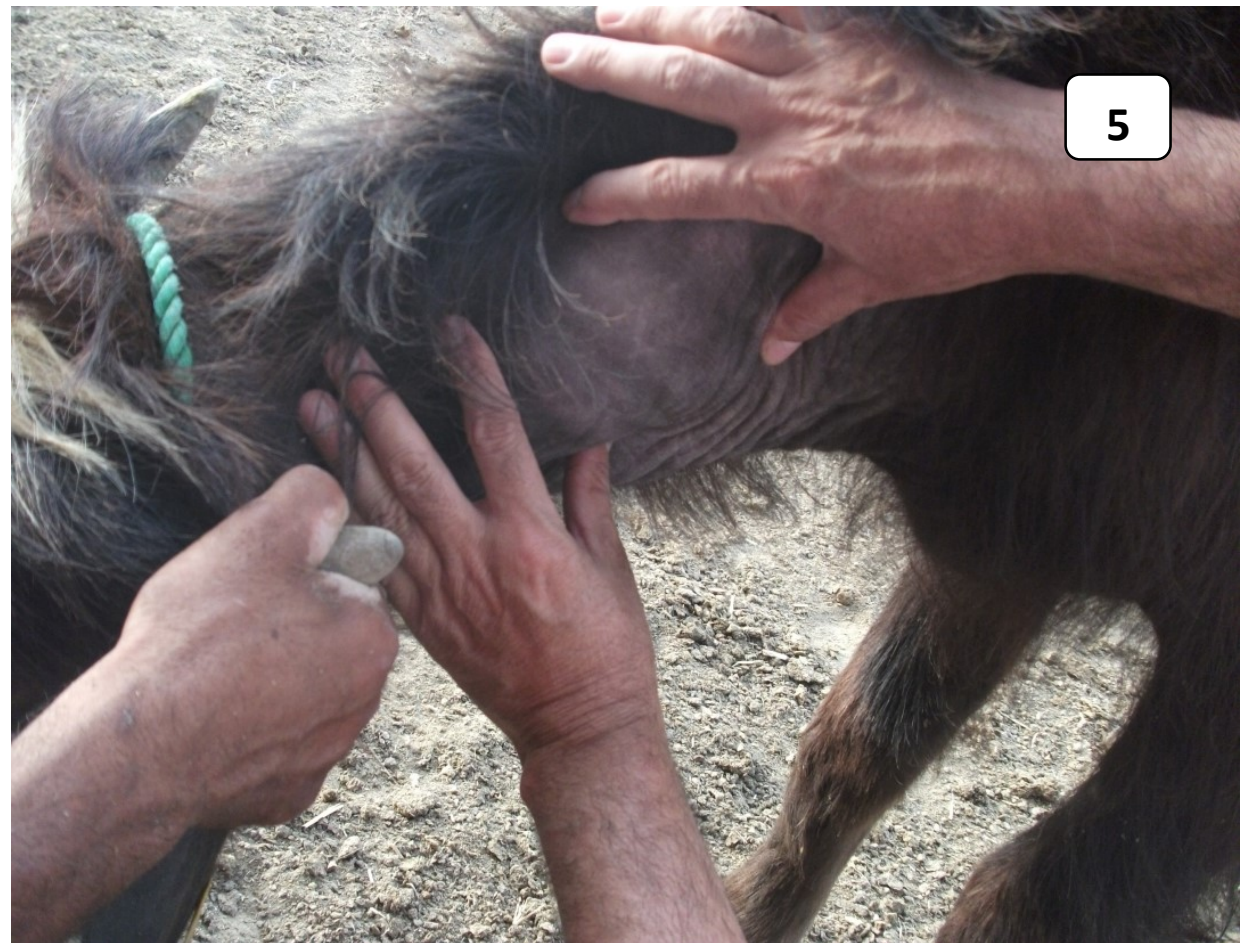

Picture (7) shows the inflammatory reaction in the neck on the animal 5 after performing the first challenge test 


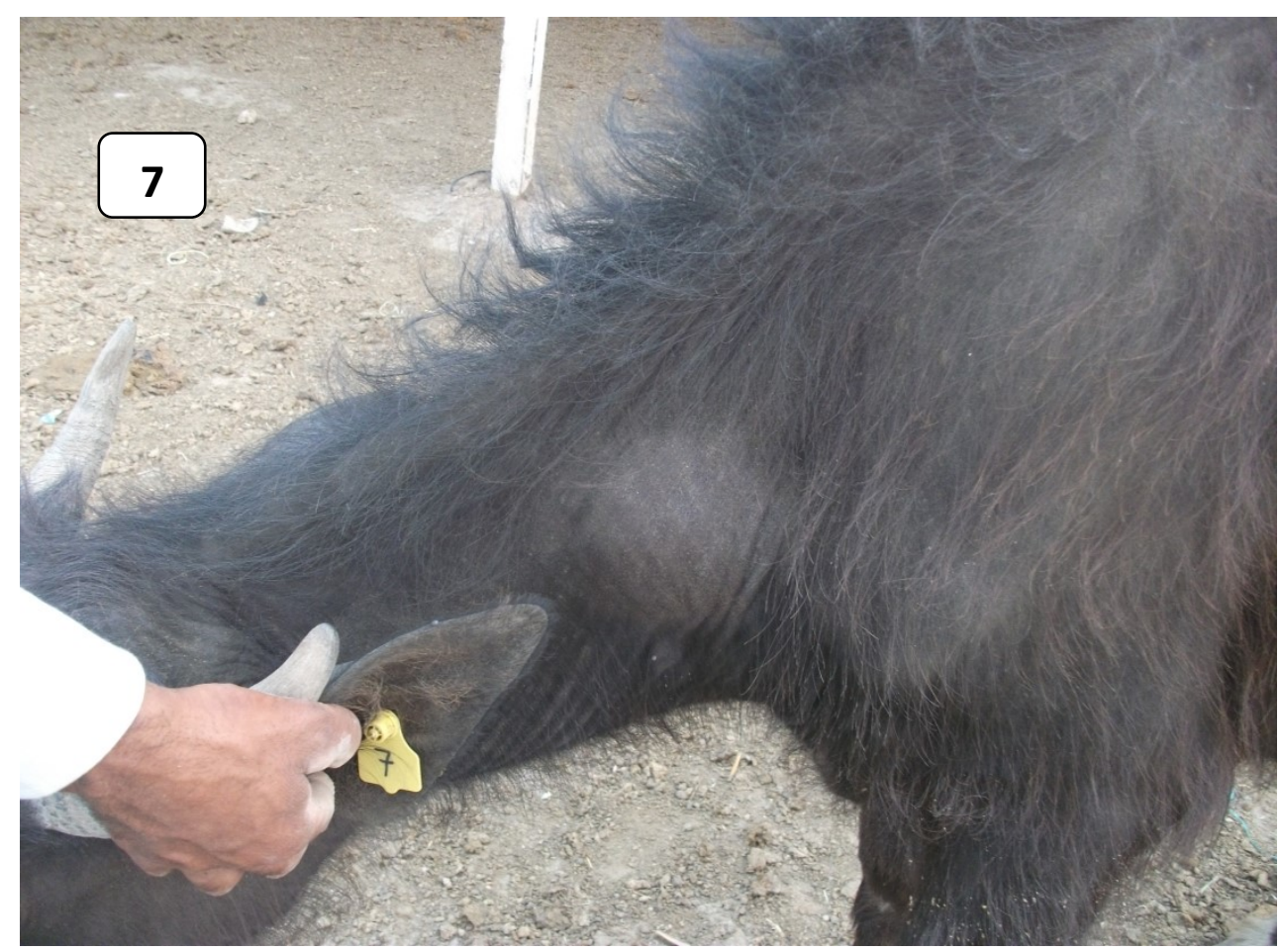

Picture (8) shows the inflammatory reaction in the neck on the animal 7 after performing the first challenge test

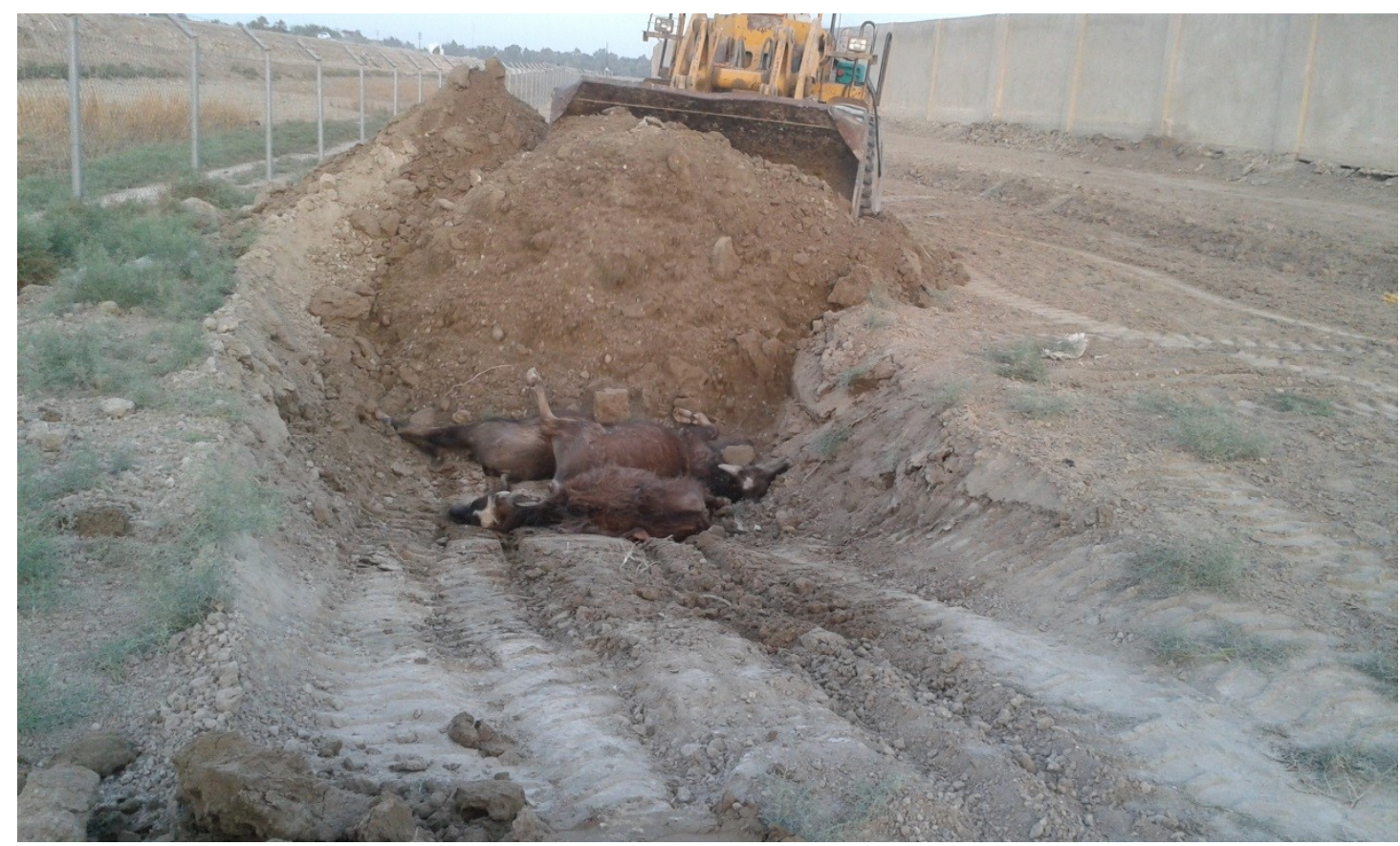

Picture (9) illustrates the scientific method for burying dead animals during the experiment and protecting the environment 


\section{University of Thi-Qar Journal of agricultural research}

ISSN Onlin:2708-9347, ISSN Print: 2708-9339 Volume 10, Issue 1 (2021) PP 104 -122

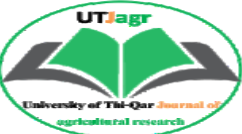

https://jam.utq.edu.iq/index.php/main $\quad$ https://10.54174/UTJagr.Vo10.N1/12

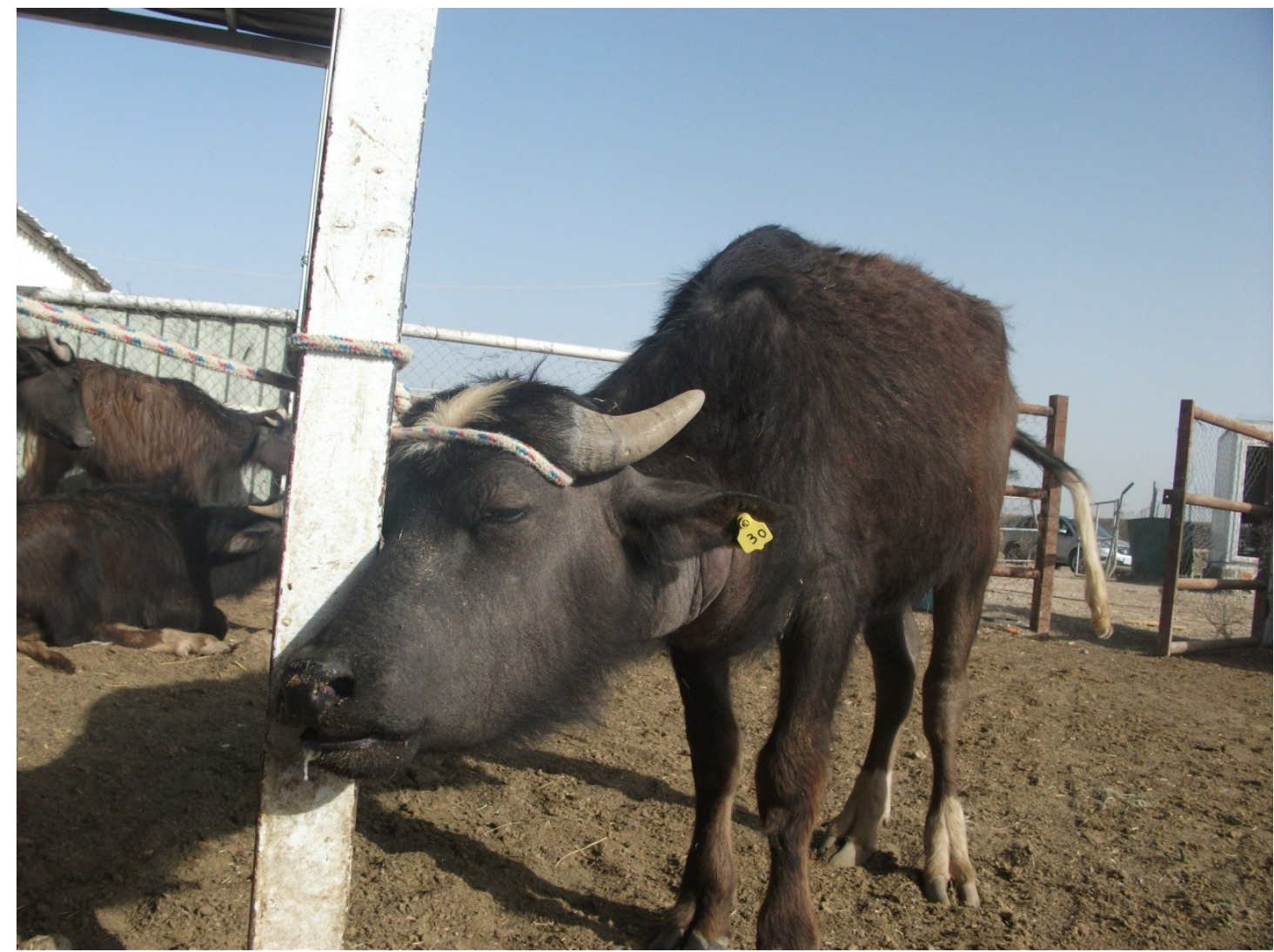

Picture (10) illustrates the clinical symptoms and the inflammatory reaction in the neck on animal No. 30 after 6 days of carrying out the first challenge test

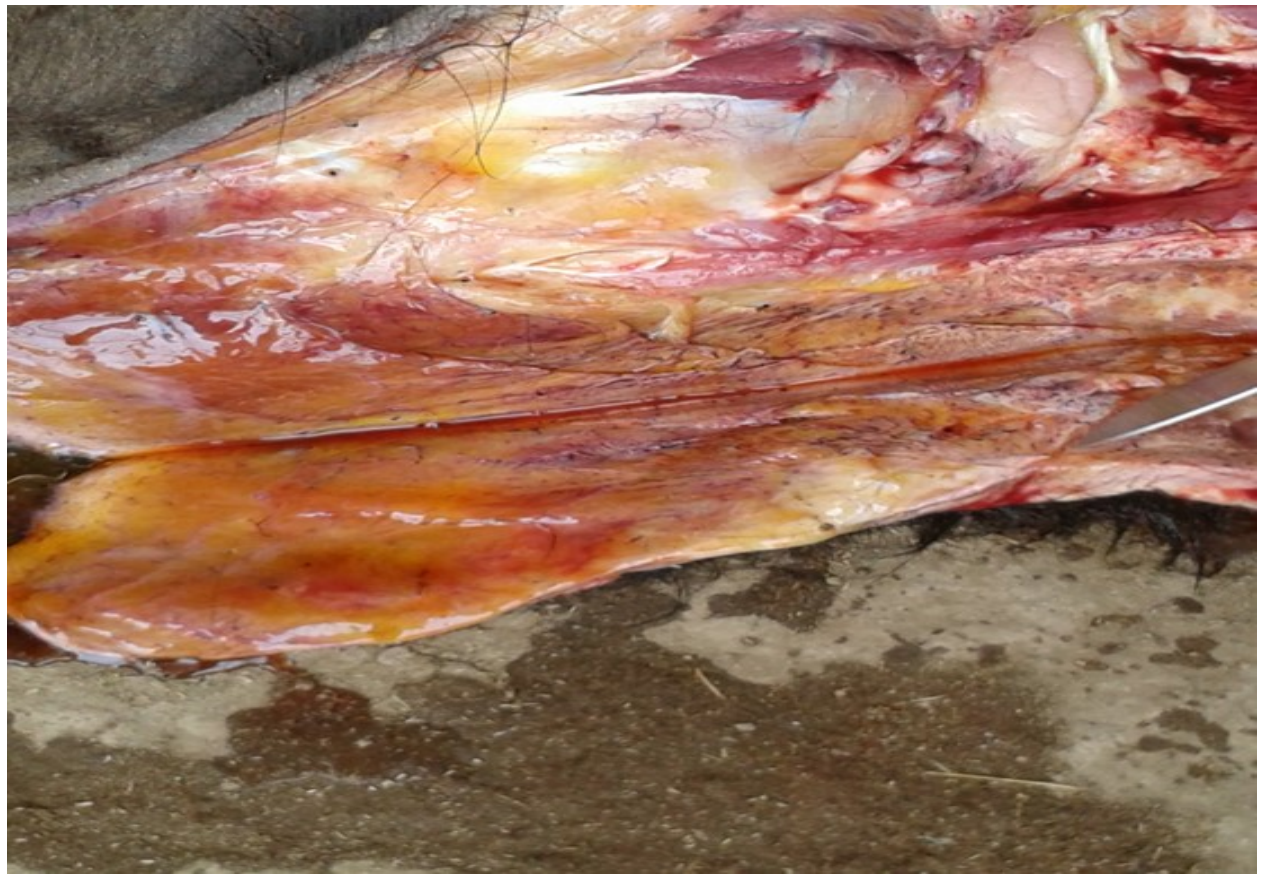

Picture (11) showing the inflammatory reaction under the skin - yellow color - in the neck on animal 30 after performing the first challenge examination 


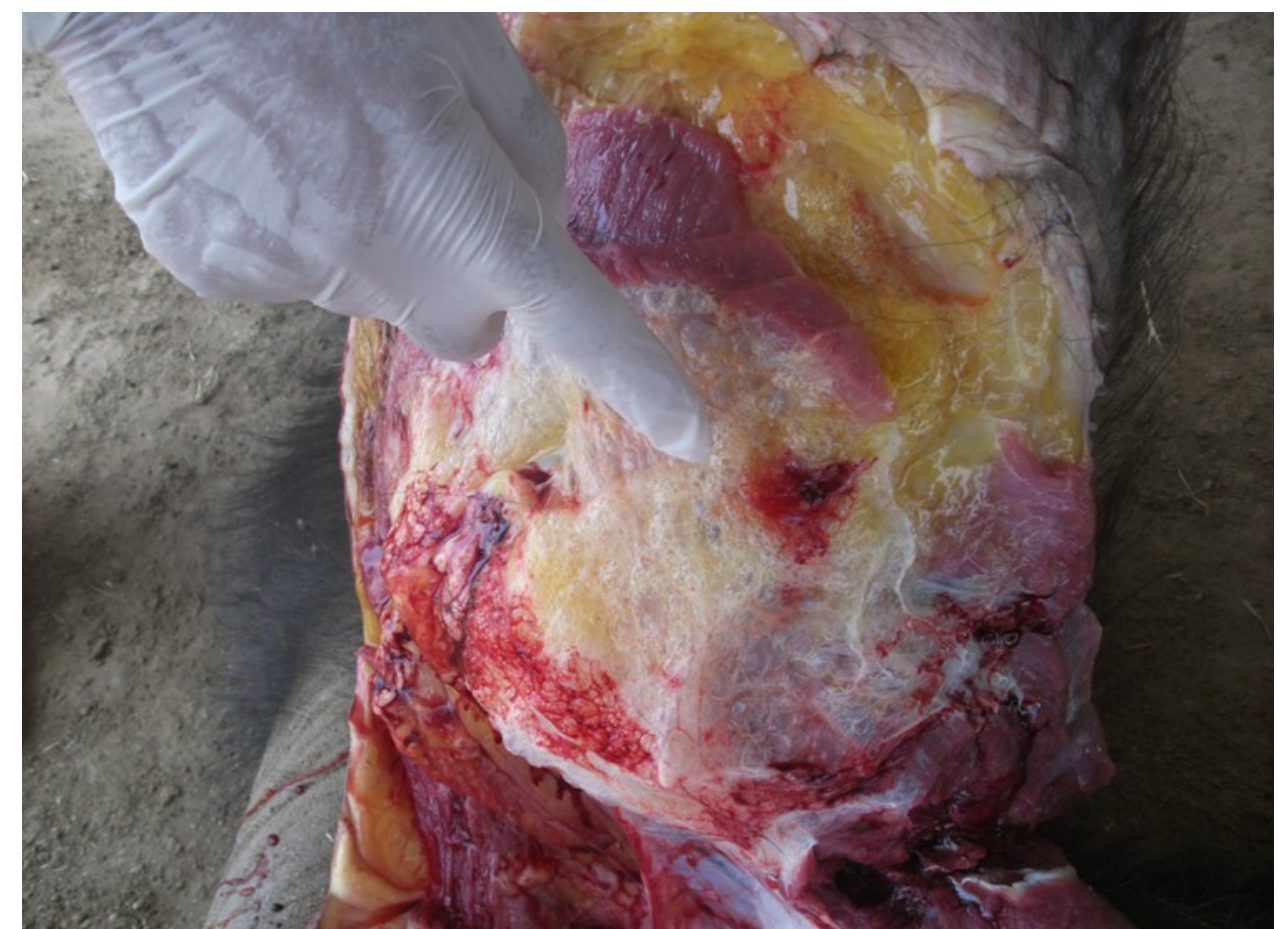

Picture (12) shows the inflammatory reaction in the shoulder on animal No. 30 after performing the first challenge test

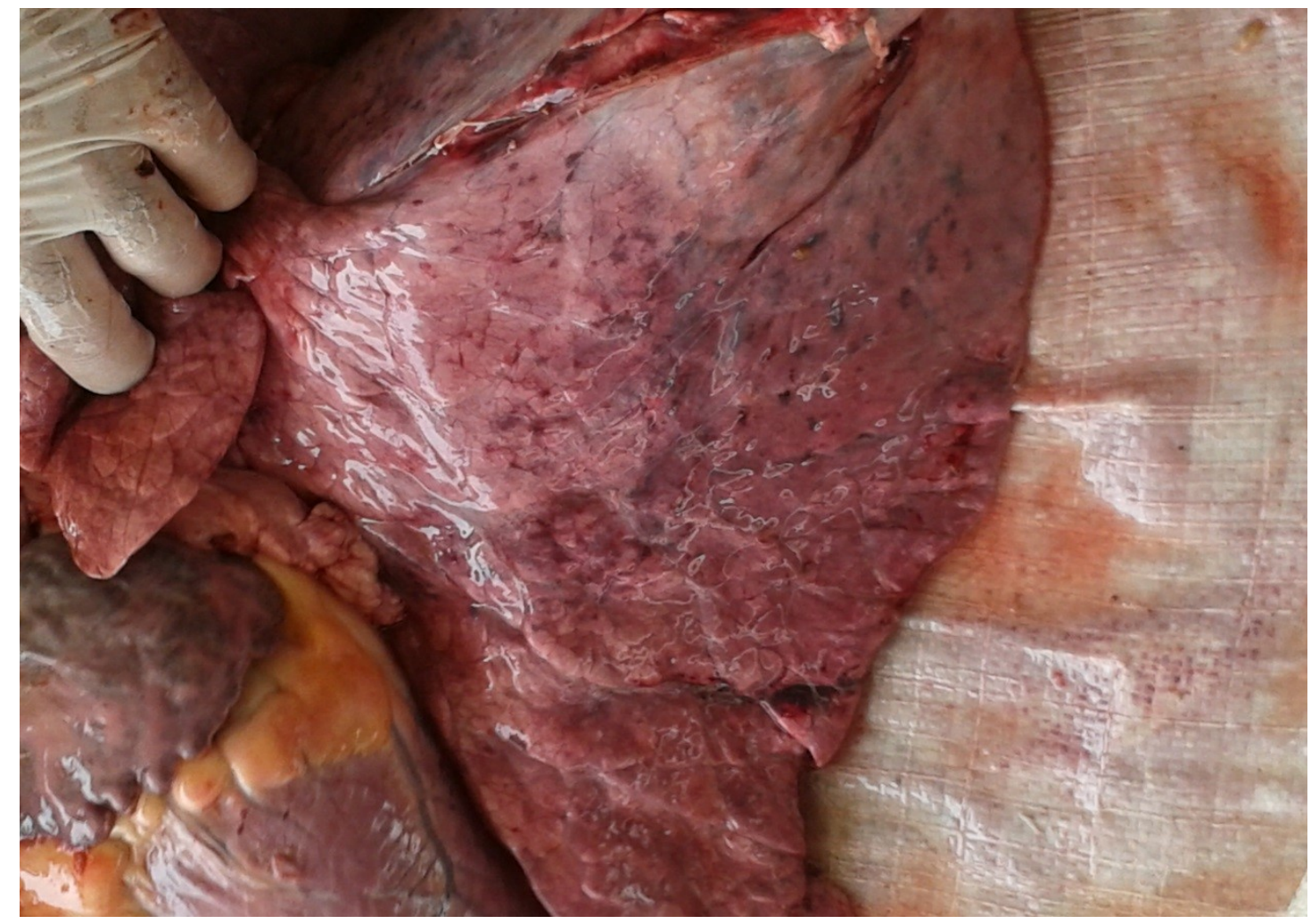

Picture (13) shows the inflammatory reaction on the lungs in animal No. 30 after performing the first challenge test 


\section{University of Thi-Qar Journal of agricultural research}

ISSN Onlin:2708-9347, ISSN Print: 2708-9339 Volume 10, Issue 1 (2021) PP 104 -122

https://jam.utq.edu.iq/index.php/main $\quad$ https://10.54174/UTJagr.Vo10.N1/12

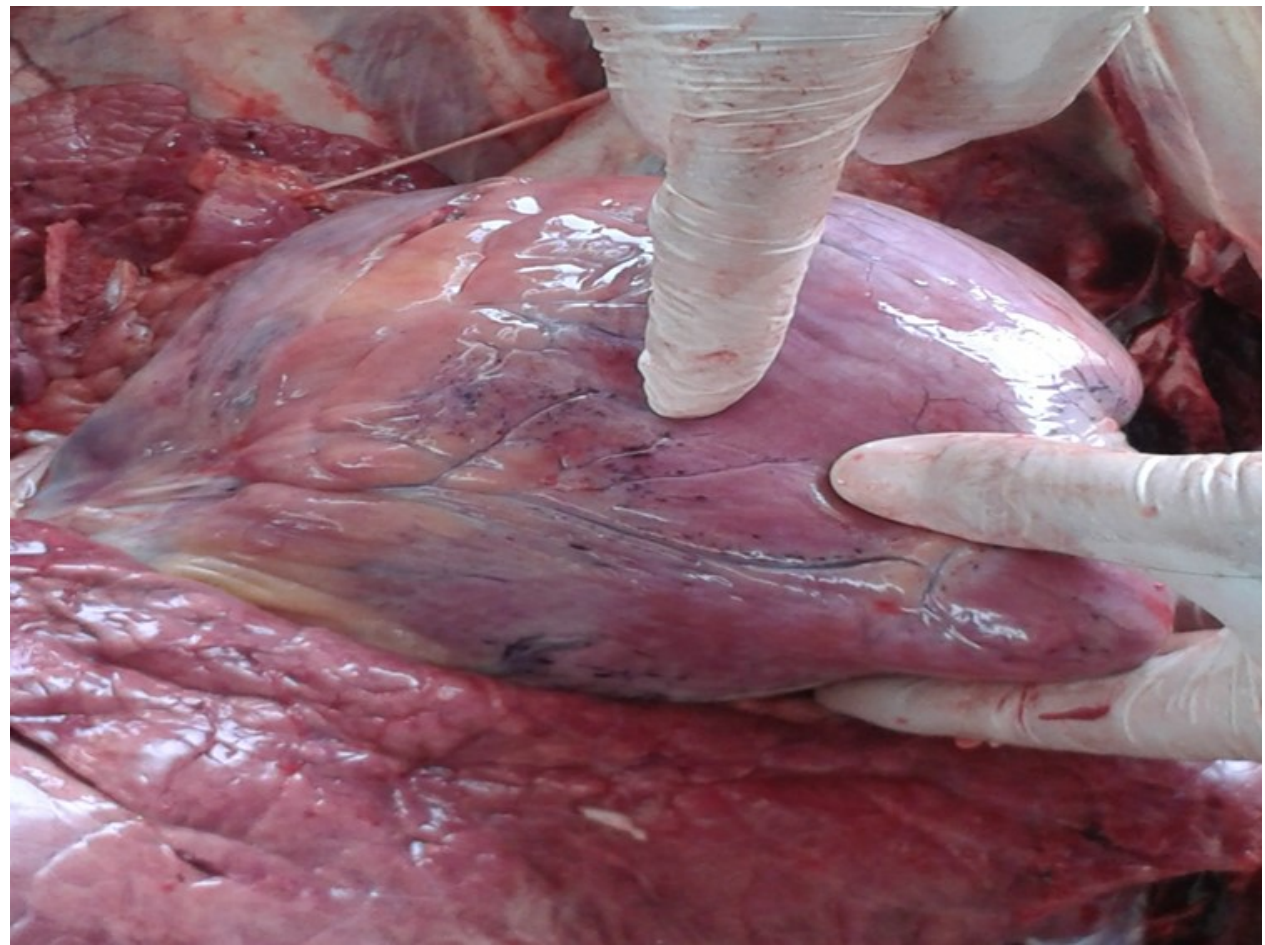

Picture (14) shows the presence of hemorrhagic spots on the heart in animal No. 30 after performing the first challenge test

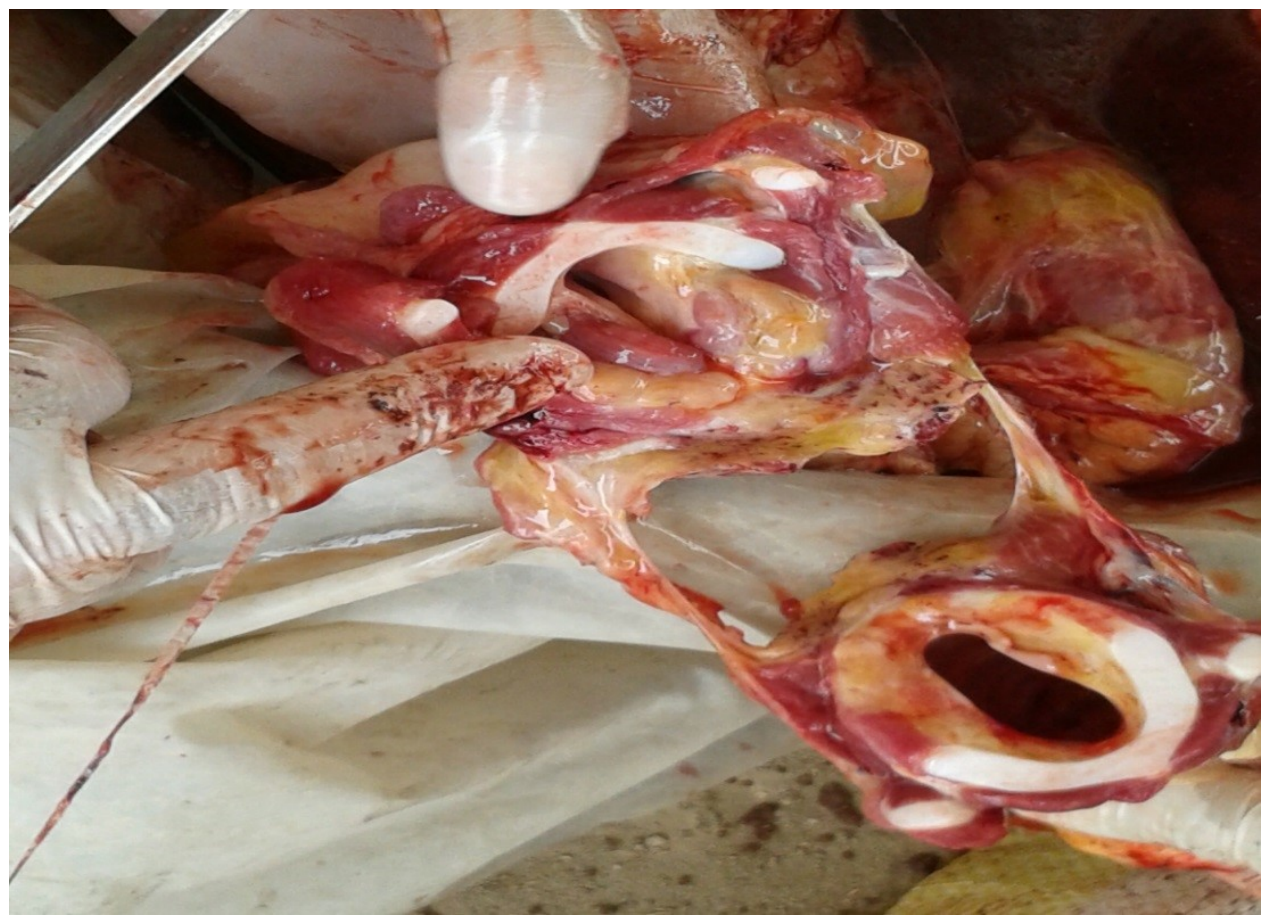

Picture (15) shows the inflammatory reaction in the larynx on animal No. 30 after performing the first challenge test 


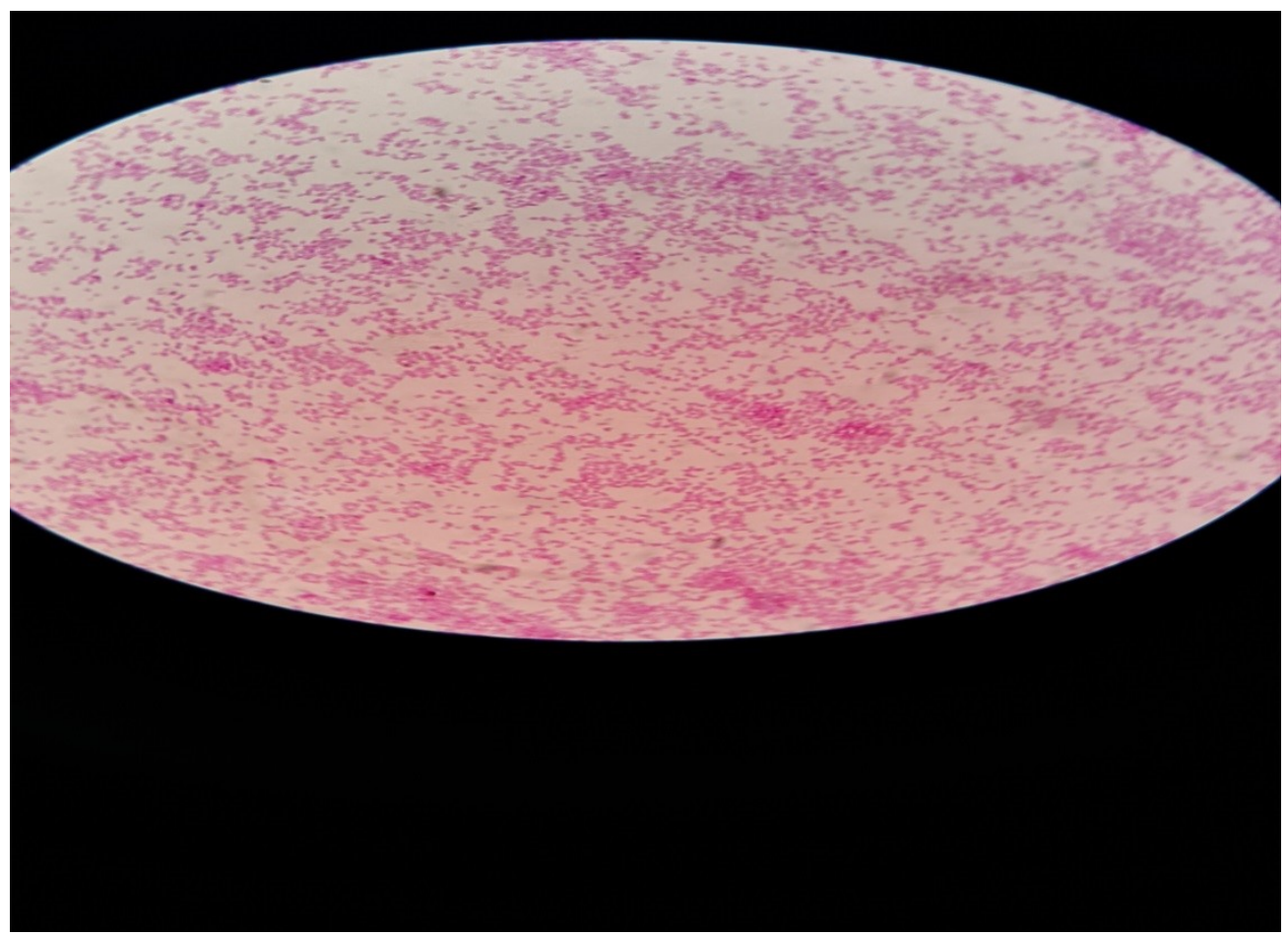

Picture (16) direct swab from the fluids of the chest cavity of animal No. 30 showing the presence of the germ after the first challenge test

\section{IV.DISCUSSION}

The three animals died, which is the positive control group that did not receive any vaccine and that received a dose of virulent bacterium within 12 hours [10] and this expresses the antigenic strength of the bacterium and the speed of its reproduction and secretion of toxins responsible[11] for killing the animal in a period of hours only. The animals seemed to be in a state of shock, temperature was below the normal range, head drooping and fluids coming out of the mouth and nose, lethargy and complete interruption of appetite and stillness in one place and then lying down, severe congestion in the mucous membranes of the eyes, enlarged of lymph nodes, increase of heartbeat and breathing, then rapid decrease in breathing and heart before death, difficulty breathing and hearing voices expressing bronchitis and lungs [12], severe swelling in the area of germ injection in the neck painful, hard and hot, throat swelling was not observed clearly in the three animals, and this clinical presentation matched with another study that dealt with clinical symptoms during a natural disease epidemic [8]. The heart rate fell to $44 / \mathrm{m}$, and the body temperature was $37 \mathrm{C}^{\circ}$ before death, and the snoring and bellowing sounds were heard before the death of the animals, which is a distinctive sound for hemorrhagic septicemia in buffaloes. The death of infected animals could be sudden, as happened during this experiment, and this matches a study [13].The three animals showed pathological symptoms, after the post mortem performed, swelling of the injection site in the neck, severe congestion in the mucous membranes of the eyes, enlarged lymph nodes, sunken eyes, slight enlargement of the larynx, bleeding in the spleen, blood not coagulated, severe congestion in the lungs ,congestion and bleeding in the 
liver, inflammation of the subcutaneous tissue in the neck and the presence of inflammatory serous fluid. These results were consistent with a study conducted on buffaloes during an epidemic of disease [14].Temperature increased, as shown in Table No. 3, in all animals injected with the challenge dose compared to the negative control animals (injected with physiological salt only). As for the positive control animals (injected with the virulent bacterial challenge dose), they died before the change in their temperature was observed, and this corresponds to what came In [10]. There were no significant differences in temperature or statistically significant in the groups of vaccinated animals, and this could be justified by the animals' resistance to the germ and preventing infection with it, except in animal No. (30) where it reached $\left(42 \mathrm{C}^{\circ}\right)$ on the fourth day and then died after that and this clinical presentation is consistent with what It occurs during natural infection, as temperatures rise in the acute phase of the disease and suffer from high fever. As for the rest of the animals in the three groups, they reached the highest degree $\left(41 \mathrm{C}^{\circ}\right)$ and then decreased $\left(40 \mathrm{C}^{\circ}\right)$ or less $(15)$. Animal mortality, clinical symptoms, and local interaction were used to characterize animal resistance to the challenge dose and the efficacy of the vaccine type in buffaloes immunization against hemorrhagic septicemia. Animal No. 30 showed typical clinical and pathological symptoms. swelling developed in the fifth day after performing the first challenge test and extended to cover the neck and part of the shoulder. On the sixth day, the symptoms increased with congestion in the eyes, hearing a s in snoring in breath, the swelling spread to the entire head, the front of the chest and the front legs, the inability to stand with the head drooping and then the animal lying down with strong snoring and drooling saliva from the mouth and fluids from the nose, then the animal died on the evening of the same day.This animal was used as a model for the emergence of pathological symptoms, as it showed all the clinical symptoms of the disease due to its long survival, which allowed the observation of pathological changes when the important post mortem , of subcutaneous tissue inflammation and swelling and the presence of yellow blood serum fluids (in the swelling areas) was performed. Severe inflammation of the lungs, black spots on their surface and bloody serous fluids in the chest cavity. Hemorrhagic patches on the heart muscle (petechial hemorrhage) and blood clots in the heart only, laryngotreachitis ,severe congestion in the small intestine and enlarged mesenteric lymph nodes. Pictures (11-15) show the pathological symptoms of animal No. 30 Samples were collected from Animal No. 30. From the heart blood and fluid accumulated in the thoracic and subcutaneous cavity for bacterial culture, the presence of the germ was confirmed. The second challenge test was performed after six months of inoculation with the booster dose (and seven months after the oil vaccine dose), but using a challenge dose with a concentration less than the first challenge $\left(8^{10}\right)$ bacteria $/ \mathrm{cm}^{3}$ to rely on clinical symptoms only without killing animals. The second control animals passed the challenge test because they resisted the germ, through the survival of two animals and the death of only one animal. Post mortem of the dead animal was performed, the germ was isolated and examined under a microscope and the colonies' characteristics were viewed to confirm the cause. These results were either due to the immunity of the animals as a result of the animals being affected by local bacterial growth because they were mixed with the animals during the first challenge test or subclinical infection if it did not appear severe clinical symptoms observed during the first challenge test, and it may be the presence of immune memory cells that made them respond quickly immunologically without the appearance of any symptoms. 


\section{Conclusions}

We can depend on animal mortality, clinical symptoms and local interaction to distinguish animal resistance to the challenge test and the efficacy of the vaccine type in immunization of buffaloes against hemorrhagic septicemia. Clinical and pathological symptoms may be used on the field diagnosis of the disease and are considered as enhancement for bacterial diagnosis.

\section{REFERENCES:}

1. Benkirane, A. and DE ALWIS, M.C.L(2002). Haemorrhagic septicemia, its significance, prevention and control in Asia . Vet. Microbiol., 41: 213-219.

2. Chandrasekaran, S., Kennett, L., Yeap, P. C, Muniandy, N., Rani, B. and Mukkur, T. K1994). Characterization of immune response and duration of protection in buffaloes immunized with haemorrhagic septicemia vaccines. Vet. Microbiol, 41(3):213-9.

3. Ali, Z., Muhammad, K., Hussain, I. and Hameed E(2000). Antibody response of buffaloes to haemorragic septicemia vaccine . Int. J. of Agri. \& Biol., 3:183-186

4. Albaek, B., Eriksen, L., Rimler, R. B., Leifsson, P. S., Basse, A., Christiansen, T. and Eriksen E(2009). Typing of Pasteurella multocida from haemorrhagic septicemia in Danish fallow deer (Damadama). APMIS, 107: 913-920.

5. Muneer, R., Akhtar, S. and Afzal(1994). M.. Evaluation of three oil-adjuvant vaccines against Pasteurella multocida in buffalo calves . Rev. Sci. tech. off. Int. Epiz. , 13 (3): 837-843

6. Rosen, M. N(1981). Pasteurellosis Infectious Diseases of Wild Animals, Second Ed. Davis J.B., Karstak L.H. \& Trainer D.O., eds. Iowa State University Press, Ames, Iowa, USA, 244-252.

7. . Naz, A., Hanif, A., Maqbool, S. and Muhammad, K(20120. Isolation, characterization and monitoring of antibiotic resistance in Pasteurella multocida isolates from buffalo ( Bubalus bubalis ) herds around Lahore . The Journal of Animal and Plant Sciences., 22: 242-245 .

8-. Jalil Abed Ghati, Khawla Ghani and Magda Saeed (2010). Diagnosis of hemorrhagic sepsis in buffaloes in the marshes of southern Iraq, 2008. Al-Qadisiyah Journal of Veterinary Science. Volume 9. Issue 2. Page 62-68.

9. Manual OF Diagnostic Tests and Vaccines for Terrestrial Animals. $6^{\text {th }}$ ed. Vol. 2 . 2008 . (OIE) .739-751.

10-Oie.terresterial manual (2018).Heamorrhagic septicemia.Chapter 3-4-10.

11-N U Horadagoda, J C Hodgson, G M Moon, T G Wijewardana and P D Eckersall (2001). Role of endotoxin in the pathogenesis of haemorrhagic septicaemia in the buffalo. Microb Pathog. Mar;30(3):171-8. Doi: 10.1006/mpat.2000.0423

12- S Annas, M Zamri-Saad, F F A Jesse and Z Zunita (2015).Comparative clinicopathological changes in buffalo and cattle following infection by Pasteurella multocida B:2. Microb Pathog. Nov;88:94-102. Doi: 10.1016/j.micpath. 08.009.

13- Eric Lim Teik Chung, et. al(2019). Responses of pro-inflammatory cytokines, acute phase proteins and cytological analysis in serum and cerebrospinal fluid during haemorrhagic septicaemia infection in buffaloes. Trop Anim Health Prod.Jul;51(6):1773-1782. 
14- Ahrar Khan, Muhammad Kashif Saleemi, Muhammad Zargham Khan, Shafia Tahseen Gul, Muhammad Irfan and Muhammad Shahbaz Qamar. (2013).Hemorrhagic Septicemia in Buffalo (Bubalus bubalis) Calves Under Sub-Tropical Conditions in Pakistan ). Department of Pathology, University of Agriculture, Faisalabad, Pakistan , Institute of Animal Nutrition and Feed Technology, University of Agriculture, Faisalabad, Pakistan.

15-Eric Lim Teik Chung, Faez Firdaus Jesse Abdullah, Ali Dhiaa Marza, Wessam Monther Mohammed Saleh ${ }^{1}$, Hayder Hamzah Ibrahim, Yusuf Abba, Mohd Zamri-Saad, Abd Wahid Haron, Abdul Aziz Saharee, Mohd Azmi Mohd Lila and Mohd Jefri Norsidin (2016). Clinico-pathology, hematology and biochemistry responses in buffaloes towards Pasteurella multocida type B: 2 immunogen 122errestrial122haride via oral and intravenous routes of infection. Microb Pathog. 91:141-54. Doi: 10.1016/j.micpath. 